\title{
Tuberculosis associated factors caused by Mycobacterium tuberculosis of the $\mathrm{RD}^{\text {Rio }}$ genotype
}

\author{
Eloise Brasil Moraes ${ }^{1,2} /{ }^{+}$, Letícia Slompo 1 , Amanda Juliane Finardi ${ }^{12}$, Heloisa da Silveira Paro Pedro ${ }^{3}$, \\ Luciana Ruiz ${ }^{4}$, Harrison Magdinier Gomes ${ }^{5}$, Virginia Bodelão Richini ${ }^{4}$, Philip Suffys ${ }^{5}$, \\ Carlos Magno Castelo Branco Fortaleza ${ }^{2}$, Ricardo Cavalcanti ${ }^{2}$, Ida Maria Foschiani Dias Baptista ${ }^{1,2}$
}

\author{
'Instituto Lauro de Souza Lima, Divisão de Pesquisa e Ensino, Equipe Técnica de Microbiologia, Bauru, SP, Brasil \\ ${ }^{2}$ Universidade Estadual Paulista Júlio de Mesquita Filho, Faculdade de Medicina de Botucatu, Doenças Tropicais, Botucatu, SP, Brasil \\ ${ }^{3}$ Instituto Adolfo Lutz, Centro de Laboratório Regional de São José do Rio Preto, Núcleo de Ciências Biomédicas, São José do Rio Preto, SP, Brasil \\ ${ }^{4}$ Instituto Adolfo Lutz, Centro de Laboratório Regional de Bauru, Núcleo de Ciências Biomédicas, Bauru, SP, Brasil \\ ${ }^{5}$ Fundação Oswaldo Cruz-Fiocruz, Laboratório de Biologia Molecular aplicada a Micobactérias, Rio de Janeiro, RJ, Brasil
}

BACKGROUND Tuberculosis (TB) continues to be a disease that affects many countries around the world, including Brazil.

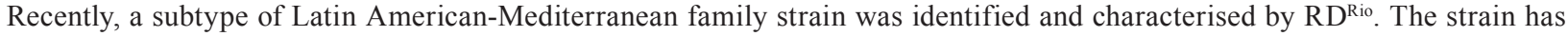
been associated with different characteristics of the disease.

OBJECTIVES In the present study we investigated the association of epidemiological, clinical, radiological and bacteriological variables with pulmonary tuberculosis caused by $\mathrm{RD}^{\mathrm{Rio}}$ Mycobacterium tuberculosis strain in large regions of São Paulo.

METHODS We conducted a cross-sectional study in 530 patients with pulmonary tuberculosis, diagnosed using sputum culture, from two regions of the São Paulo state in Brazil. The samples were brought to São Paulo reference laboratories for epidemiological, clinical, radiological and bacteriological analyses, and the data were obtained from a TB notification system. $\mathrm{RD}^{\mathrm{Rio}}$ genotyping and Spoligotyping of the samples were performed. For the analysis of the categorical variables we used the chisquare test or the Fisher's exact test, and for the continuous variables, the Mann-Whitney test. In addition, a logistic regression was used for multivariate analysis. Differences with $\mathrm{p}<0.05$ were considered significant.

FINDINGS The RD Rio deletion was identified in 152 (28.7\%) samples. In the univariate analysis, both the age groups above 25 years and alcohol consumption were associated with the $\mathrm{RD}^{\text {Rio }}$ deletion. The multivariate analysis confirmed the association of the $\mathrm{RD}^{\mathrm{Rio}}$ deletion with the age groups: $25-35$ years old [OR: $\left.2.28(1.02-5.07 ; \mathrm{p}=0.04)\right]$ and 36-60 years old $(\mathrm{OR}$ : 2.36 $(1.11-5.05)$; $\mathrm{p}=0.03$ ], and also with alcohol consumption [OR: $1.63(1.05-2.54) ; \mathrm{p}=0,03]$.

MAIN CONCLUSIONS In this study, we identified new factors associated with the M. tuberculosis of the $\mathrm{RD}^{\mathrm{Rio}}$ deletion strains infection.

Key words: Mycobacterium tuberculosis - RD ${ }^{\text {Rio }}$ - tuberculosis - genotyping - epidemiology

Tuberculosis (TB) is an infectious disease that kills nearly 2 million people each year. The disease emerged about 70,000 years ago, with the migration of anatomically modern humans from Africa, and expanded as a result of the increase in human population density during the Neolithic (Comas et al. 2013). TB continues to be a global epidemic, and if left untreated, has a mortality rate of $\sim 70 \%$ in people with positive sputum smears (Fogel 2015).

Although the incidence of tuberculosis has decreased in recent years, 9.6 million new cases and 1.5 million deaths were reported worldwide in 2014 (WHO 2014). Brazil is among the 22 countries with the highest TB incidence worldwide. The majority of the cases reported in Brazil were concentrated in the Southeast, where the state of São Paulo (SP) accounted for $20 \%$ of the disease incidence in the country (Wysochi et al. 2016).

doi: 10.1590/0074-02760160347

Financial support: FAPESP (no 2013/09538-3)

+ Corresponding author: eloise.moraes@hotmail.com

Received 30 July 2016

Accepted 7 November 2016
Molecular typing, based on genetic markers, allows the rapid identification of Mycobacterium tuberculosis complex strains (MTC) and provides useful tools for examining the transmission and the development of the mycobacteria (Sola et al. 2001, Brosch et al. 2002, Gagneux et al. 2006). A polymerase chain reaction (PCR) identification based on the amplification of multiple deleted loci can distinguish between the MTC species (Huard et al. 2003).

Lazzarini et al. (2007) reported that MTC isolates, designated as $\mathrm{RD}^{\mathrm{Rio}}$, were found to contain a chromosomal deletion of more than $26 \mathrm{~kb}$. The authors reported that further analysis of the $\mathrm{RD}^{\mathrm{R} \text { io }}$ strains with a spoligotyping molecular technique confirmed that all isolates belong to Latin American-Mediterranean family (LAM). The presence of $\mathrm{RD}^{\mathrm{Rio}} M$. tuberculosis isolates have been reported in at least 18 other countries in Europe, Africa, and the Americas, in which all the isolates belonged to the LAM genotype of the Euro-American lineage (Gibson et al. 2008, Weisenberg et al. 2012). The $\mathrm{RD}^{\mathrm{Rio}}$ M. tuberculosis is the most common cause of $\mathrm{TB}$ in Rio de Janeiro and other regions of Brazil (Lazzarini et al. 2008, Oelemann et al. 2011). 
Recent studies suggest that $M$. tuberculosis strains are well adapted to human populations and that they are older and have a greater genetic diversity than previously thought (Alix et al. 2006). This diversity may have an important effect in different clinical and epidemiological aspects of tuberculosis. However, the current knowledge about the influence of TB strain diversity on the development of the disease is still scarce (Barbosa et al. 2012). Considering this, in the present study we investigated the association of epidemiological, clinical, radiological and bacteriological variables with pulmonary tuberculosis caused by $\mathrm{RD}^{\mathrm{Rio}} M$. tuberculosis strains in large regions of São Paulo.

\section{PATIENTS AND METHODS}

A cross-sectional population-based study was conducted on pulmonary tuberculosis cases reported in the period 2012-2014. Two regions of the state of São Paulo were considered for this study: 69 municipalities belonging to the Regional Health Department (DRS) Section VI (Bauru) and 102 municipalities of the DRS Section XV (São José do Rio Preto).

A total of 530 tuberculosis patients with positive sputum cultures for M. tuberculosis were recruited. Since the detection of the $\mathrm{RD}^{\mathrm{Rio}}$ deletion is only possible using the isolated culture, patients without sputum culture were not included in the study. The patients' data were obtained through the Notification System and Monitoring of Tuberculosis Cases (TB-WEB) of the State Department of Health from the state of São Paulo - Brazil (SES/CCD/CVE). The epidemiological, clinical, radiological and bacteriological data for each patient were filled in the TB-WEB system for the epidemiological surveillance in each municipality.

M. tuberculosis culture samples - The M. tuberculosis culture samples were collected in the laboratories of the Adolfo Lutz Institute from both DRS Sections (VI and XV) and brought to the Instituto Lauro de Souza Lima for analysis. Biochemical characterisation and multidrug-resistance tests (INH, RMP, SM, and EMB) were performed as recommended by the Ministry of Health of Brazil. The susceptibility of the samples to PZA was tested separately by means of the pyrazinamidase assay (MS/SVS/DVE 2008).

Multiplex PCR and Spoligotyping of RD Rio strains The identification of $\mathrm{RD}^{\mathrm{Rio}}$ deletions was performed as described by Lazzarini et al. (2007) and Gibson et al. (2008). The RD Rio and wild type (WT) genotypes were identified by the detection of the 1175 and 530 bp standard bands, respectively. Sample spoligotyping was performed according to the method reported by Kamerbeek et al. (1997). The spoligotype patterns were recorded in an octagonal code and in a 43-digit binary format, representing 43 spacers (Filliol et al. 2002). The M. tuberculosis patterns were compared with the SpolDB4 database (Brudey et al. 2006) of the Pasteur Institute in Guadeloupe (http://www.pasteur-guadeloupe.fr:8081/ SITVITDemo) for type classification.

Statistical analysis - For the bivariate evaluation of categorical variables we used the chi-square test or the
Fisher's exact test, whereas for continuous variables analyses, the Mann-Whitney test was performed using the Epi Info version 3.5.4. These methods were applied to compare the results of the regions of Bauru (DRS-VI) and São José do Rio Preto (DRS-XV). In addition, a multivariate analysis with a logistic regression function was used to investigate the association between the presence of the RDRio marker deletion and the epidemiological variables.

Variable selection for the multivariate analysis was performed following a hierarchical procedure. Initially, the demographics were considered as distal variables. The variables that were significant $(p<0.05)$ were maintained and analysed in conjunction with the comorbidities and lifestyle variables, which were considered as intermediate variables. The variables which in this analysis resulted in a $p<0.05$ were retained and further analysed together with the proximal variables (clinical, bacteriological and radiological). For the logistic regression, the selected variables were presented in terms of the odds ratios and their $95 \%$ confidence interval. This analysis was performed using the SPSS software version 20 considering significant variables for $\mathrm{p}<0.05$.

\section{RESULTS}

In the period covered by this study, 530 patients with positive sputum cultures for tuberculosis were reported: 176 from Bauru and 354 from São José do Rio Preto. Because this study used secondary data, it was not possible to obtain all the information from all the patients. The epidemiological, clinical, radiological and bacteriological data of the patients of both regions are described in Table I.

The analysis resulted in a higher prevalence of patients of African descent (16.1 vs. 6.7\%; $\mathrm{p}=0.003)$ with pulmonary tuberculosis only (99.4 vs. $94.8 \% ; p=0.02$ ) and a higher rate of treatment abandonment (18.3 vs. $7.4 \% ; p=0.001)$ in the DRS-VI Bauru region. On the other hand, smokers (31.0 vs. $13.3 \%$; $\mathrm{p}=0.0001)$ prevailed in the cases detected in the municipalities of the DRS-XV São José do Rio Preto region.

The sensitivity to antituberculosis drugs is shown in Table II. The incidence of drug resistance was higher in the DRS-VI Bauru region (20.4 vs. $10.2 \%$; $p=0.08$ ), with significant data for pyrazinamide resistance $(50.0$ vs. $4.7 ; \mathrm{p}=0.02$ ).

The $\mathrm{RD}^{\mathrm{Rio}}$ deletion was identified in 152 (28.7\%) culture samples. The analysis of the factors associated with the presence of this deletion was analysed in 429 patients only. The rest of the patients were not admitted in the analysis for the lack of data. In the univariate analysis, the age groups above 25 years and alcohol-using patients were associated with the presence of the $\mathrm{RD}^{\mathrm{Rio}}$ deletion, while a history of tuberculosis and drug resistance were marginally significant (Table III).

The multivariate analysis confirmed the association between $\mathrm{RD}^{\mathrm{Rio}}$ deletion and the 25-35 years old age group [OR: 2.28 (1.02 to 5.07)] and the 36-60 year old age group [OR: 2.36 (1.11 to 5.05)], as well as with elitism [OR: 1.63 (1.05 to 2.54)], Table IV. Spoligotyping results were unsatisfactory due to problems with the membranes used for sample hybridization. Based on the 


\section{TABLE I}

Epidemiological, clinical, radiological and bacteriological data of 530 tuberculosis patients from two regions of the state of São Paulo, Brazil

\begin{tabular}{|c|c|c|c|}
\hline & Bauru (DRS-VI) & São José do Rio Preto (DRS-XV) & $\mathrm{p}$ value \\
\hline Male & $130 / 176(82,8)$ & $281 / 354(80,1)$ & 0,54 \\
\hline Age (years) & $35,0(19,0-74,0)$ & $37,0(14,0-80,0)$ & 0,05 \\
\hline \multicolumn{4}{|l|}{ Ethnicity } \\
\hline white & $79 / 137(57,7)$ & $195 / 314(62,1)$ & 0,43 \\
\hline black & $22 / 137(16,1)$ & $21 / 314(6,7)$ & 0,003 \\
\hline brown & $35 / 137(25,5)$ & $94 / 314(29,9)$ & 0,40 \\
\hline indian & $1 / 137(0,7)$ & $0 / 314(0,0)$ & 0,30 \\
\hline yellow & $0 / 137(0,0)$ & $4 / 314(1,3)$ & 0,23 \\
\hline \multicolumn{4}{|l|}{ Schooling } \\
\hline unlettered & 4/106 $(3,8)$ & $12 / 306(3,9)$ & 0,60 \\
\hline $1-3$ years & $13 / 106(12,3)$ & $39 / 306(12,7)$ & 0,96 \\
\hline $4-7$ years & $47 / 106(44,3)$ & $133 / 306(43,5)$ & 0,96 \\
\hline $8-11$ years & $29 / 106(27,4)$ & $109 / 306(35,6)$ & 0,15 \\
\hline 12 - 14 years & 2/106 (1,9) & $8 / 306(2,6)$ & 0,50 \\
\hline \multicolumn{4}{|l|}{ Comorbidities } \\
\hline diabetes mellitus & $8 / 128(6,3)$ & $22 / 329(6,7)$ & 0,96 \\
\hline HIV infection & $12 / 125(9,6)$ & $56 / 324(17,3)$ & 0,06 \\
\hline alcoholism & $32 / 129(24,8)$ & $96 / 329(29,2)$ & 0,41 \\
\hline smoking & $17 / 128(13,3)$ & $102 / 329(31,0)$ & 0,0001 \\
\hline drogadiction & $42 / 129(32,6)$ & $88 / 324(27,2)$ & 0,30 \\
\hline mental disease & $1 / 90(1,1)$ & $8 / 323(2,5)$ & 0,38 \\
\hline Prisoner & $34 / 109(31,2)$ & $94 / 228(41,2)$ & 0,09 \\
\hline History of tuberculosis & $34 / 132(25,8)$ & $69 / 328(21,0)$ & 0,32 \\
\hline \multicolumn{4}{|l|}{ Tuberculosis forms } \\
\hline pulmonary & $164 / 165(99,4)$ & $311 / 328(94,8)$ & 0,02 \\
\hline extrapulmonary & $1 / 165(0,6)$ & $16 / 328(4,9)$ & 0,02 \\
\hline Positive sputum smear & $96 / 134(71,6)$ & $198 / 310(63,9)$ & 0,13 \\
\hline \multicolumn{4}{|l|}{ Chest X-ray } \\
\hline normal & $7 / 93(7,5)$ & $24 / 222(10,8)$ & 0,49 \\
\hline cavitary & $23 / 93(24,7)$ & $74 / 222(33,3)$ & 0,16 \\
\hline suggestive of tuberculosis & $63 / 93(67,7)$ & $124 / 222(55,9)$ & 0,06 \\
\hline Treatment abandonment & $23 / 126(18,3)$ & $24 / 325(7,4)$ & 0,001 \\
\hline Deaths (all causes) & $7 / 126(5,6)$ & $17 / 325(5,2)$ & 0,92 \\
\hline
\end{tabular}

TABLE II

Drug resistance in tuberculosis patients from two regions of the state of São Paulo, Brazil

\begin{tabular}{lccc}
\hline & Bauru & São José do Rio Preto & p value \\
\cline { 2 - 3 } No. of patients with resistance & $4 / 44(9,1)$ & $22 / 314(7,0)$ & 0,39 \\
\hline No. total of identified resistance & $9 / 44(20,4)$ & $32 / 314(10,2)$ & 0,08 \\
No. drug resistance & & & 0,24 \\
$\quad$ Rifampicin & $2 / 43(4,7)$ & $6 / 313(1,9)$ & 0,18 \\
$\quad$ Isoniazid & $3 / 41(7,3)$ & $10 / 314(3,2)$ & 0,02 \\
$\quad$ Pyrazinamide & $2 / 4(50,0)$ & $3 / 64(4,7)$ & --- \\
$\quad$ Ethambutol & $0 / 32(0,0)$ & $0 / 240(0,0)$ & 0,56 \\
$\quad$ Streptomycin & $2 / 33(6,1)$ & $13 / 238(5,5)$ & \\
\hline
\end{tabular}


TABLE III

Univariate analysis of the epidemiological, clinical, microbiological and radiological factors tassociated with the presence of $\mathrm{RD}^{\text {Rio }}$ deletion in 429 patients with tuberculosis

\begin{tabular}{|c|c|c|c|c|}
\hline \multirow[b]{3}{*}{ Male } & \multicolumn{2}{|c|}{ Deletion RD ${ }^{\text {Rio }}$} & \multirow[b]{2}{*}{$\begin{array}{l}\text { Odds ratio } \\
\text { (CI 95\%) }\end{array}$} & \multirow[b]{2}{*}{$\mathrm{p}$ value } \\
\hline & $\begin{array}{c}\text { Presence } \mathrm{n}^{\circ} \text { patients } \\
(\%)\end{array}$ & $\begin{array}{c}\text { Absence } \mathrm{n}^{\mathrm{o}} \text { patients } \\
(\%)\end{array}$ & & \\
\hline & $127(83,6)$ & $302(79,9)$ & $1,27(0,76-2,19)$ & 0,19 \\
\hline \multicolumn{5}{|l|}{ Age group } \\
\hline under 24 years* & $9(5,9)$ & $53(14,0)$ & --- & --- \\
\hline 25 - 35 years & $43(28,3)$ & $101(26,7)$ & $2,50(1,13-5,53)$ & 0,03 \\
\hline $36-60$ years & $89(58,6)$ & $202(53,4)$ & $2,59(1,22-5,48)$ & 0,01 \\
\hline over 60 years & $11(7,2)$ & $22(5,8)$ & $2,94(1,07-8,09)$ & 0,03 \\
\hline \multicolumn{5}{|l|}{ Ethnicity } \\
\hline white* & $79(52,0)$ & $195(51,6)$ & --- & --- \\
\hline brown & $35(23,0)$ & $94(24,9)$ & $0,91(0,57-1,46)$ & 0,72 \\
\hline black & $10(6,6)$ & $33(8,7)$ & $0,74(0,35-1,59)$ & 0,45 \\
\hline others & $1(0,7)$ & $4(1,1)$ & $0,61(0,06-5,60)$ & 0,66 \\
\hline \multicolumn{5}{|l|}{ Schooling } \\
\hline 1 - 3 years* & $15(9,9)$ & $37(9,8)$ & --- & --- \\
\hline 4 - 7 years & $57(37,5)$ & $123(32,5)$ & $1,14(0,58-2,24)$ & 0,69 \\
\hline $8-11$ years & $36(23,7)$ & $102(27,0)$ & $0,87(0,42-1,77)$ & 0,70 \\
\hline $12-14$ years & $1(0,7)$ & $9(2,4)$ & $0,24(0,03-2,35)$ & 0,23 \\
\hline over - years & $0(0,0)$ & $5(1,3)$ & --- & 0,97 \\
\hline unlettered & $5(3,3)$ & $11(2,9)$ & $1,12(0,33-3,78)$ & 0,85 \\
\hline Prisoner & $32(21,1)$ & $96(25,4)$ & $0,78(0,48-1,25)$ & 0,17 \\
\hline Health professional & $3(2,0)$ & $2(0,5)$ & $3,77(0,42-45,60)$ & 0,14 \\
\hline HIV & $18(11,8)$ & $50(13,2)$ & $0,88(0,46-1,60)$ & 0,39 \\
\hline Diabetes & $7(4,6)$ & $23(6,1)$ & $0,74(0,26-1,84)$ & 0,33 \\
\hline Alcoholism & $46(30,3)$ & $82(21,7)$ & $1,56(1,02-2,38)$ & 0,02 \\
\hline Smoking & $35(23,0)$ & $84(22,2)$ & $1,04(0,64-1,67)$ & 0,46 \\
\hline Mental disease & $3(2,0)$ & $6(1,6)$ & $1,24(0,19-5,93)$ & 0,50 \\
\hline Previous history of tuberculosis & $23(17,6)$ & $80(24,3)$ & $0,66(0,37-1,13)$ & 0,07 \\
\hline \multicolumn{5}{|l|}{ Year of diagnosis } \\
\hline $2012 *$ & $23(19,7)$ & $72(26,1)$ & --- & --- \\
\hline 2013 & $50(42,7)$ & $102(37,0)$ & $1,49(0,83-2,65)$ & 0,17 \\
\hline 2014 & $44(37,6)$ & $102(37,0)$ & $1,25(0,73-2,15)$ & 0,40 \\
\hline Pulmonary tuberculosis & $146(96,1)$ & $365(96,6)$ & $0,86(0,30-2,83)$ & 0,47 \\
\hline Positive sputum smear & $94(61,8)$ & $250(66,1)$ & $0,83(0,55-1,25)$ & 0,20 \\
\hline Cavitary & $24(15,8)$ & $73(19,3)$ & $0,78(0,45-1,32)$ & 0,20 \\
\hline Drug resistance & $4(2,6)$ & $22(5,8)$ & $0,43(0,10-1,32)$ & 0,08 \\
\hline
\end{tabular}

CI 95\%: confidence interval of 95\%; *: category of reference.

spoligotype analysis, $21 \mathrm{RD}^{\mathrm{Rio}}$ isolates belonged to the families LAM 1, LAM 2, LAM 3, LAM 4, LAM 5, and LAM 9, whereas the rest of the isolates were typified within the U H1, T1 and Unknown families.

\section{DISCUSSION}

TB is a global disease that affects not only individual patients, but also the community. Tuberculosis control goes beyond conventional strategies, therefore it is necessary to understand the interaction of the disease with the social and economic culture (Eufrásio et al. 2016). $M$. tuberculosis has a clonal population structure and until recently, it has been regarded to have little genetic variation (Sreevatsan et al. 1997, Hirsh et al. 2004). However, studies examining $M$. tuberculosis isolates from broader geographical distributions via whole-genome scanning revealed a cladistics phylogeographical distribution with significant variation between the main lines, each associated with a specific geographical region (Gagneux \& Small 2007, Caws et al. 2008). 


\section{TABLE IV}

Multivariate analysis of the epidemiological, clinical, microbiological and radiological factors associated with the presence of $\mathrm{RD}^{\text {Rio }}$ deletion in 429 patients with tuberculosis

\begin{tabular}{lcc}
\hline Age group & $\begin{array}{c}\text { Odds ratio } \\
(\text { CI 95\%) }\end{array}$ & p value \\
\hline under 24 years* & --- & --- \\
$25-35$ years & $2,28(1,02-5,07)$ & 0,04 \\
36 - 60 years & $2,36(1,11-5,05)$ & 0,03 \\
over 60 years & $2,69(0,96-7,52)$ & 0,06 \\
Alcoholism & $1,63(1,05-2,54)$ & 0,03 \\
\hline
\end{tabular}

CI 95\%: confidence interval of 95\%; *: category of reference.

Several studies have used genotyping assays to characterise the population structure of $M$. tuberculosis and its transmission in defined communities. The high prevalence of TB caused by identical or related strains in a community may be caused by recent introduction of isolates, increased of its virulence, or even epidemiological factors that facilitate TB transmission. However, it is still unknown how the genetic makeup of M. tuberculosis isolates determines the transmission or the severity of the disease, as only a few studies have reported this type of analysis (Coscolla \& Gagneux 2010, Vinhas et. al. 2013).

Lazzarini et al. (2007) described an M. tuberculosis strain belonging to the LAM family. The strain $\left(\mathrm{RD}^{\mathrm{Ri}}\right)$ had a large 26.3-Kb deletion (Long Sequence Polymorphism LSP), which included 10 genes, in its DNA sequence.

The prevalence of M. tuberculosis samples with an $\mathrm{RD}^{\mathrm{Rio}}$ deletion varied with the geographical location. In this study, we found this behaviour in $28.7 \%$ of the samples. These results were similar to those reported by Barbosa et al. (2012) in the city of Rio de Janeiro, in which the strain was detected in $26.5 \%$ of the cases (Barbosa et al. 2012). The occurrence of the $\mathrm{RD}^{\mathrm{Rio}}$ deletion in the samples was lower than that found in Belo Horizonte (37\%) and in Porto Alegre (38\%).

Patients in both the regions analysed in this study, DRS-VI Bauru and DRS-XV São José do Rio Preto, showed some differences. There was a higher prevalence of patients of African descent, patients with only pulmonary tuberculosis, and higher treatment-dropout rate in DRS-VI Bauru, while smokers prevailed in the municipalities of DRS-XV São José do Rio Preto. Apparently, these differences did not have an impact on the presence or absence of the $\mathrm{RD}^{\text {Rio }}$ deletion, and they may be related to the geographical characteristics of every region. In general, the strains were not drug resistant, with the DRS-VI Bauru samples possessing a greater drug resistant capacity. The resistance of the strains to pyrazinamide was higher in the latter region. However, since the number of samples was very small, this result may not be representative of the local reality.

The age groups 25-35 and 36-60 years old were associated with the presence of $\mathrm{RD}^{\mathrm{Rio}}$ deletion, indicating that these strains are less infectious in young individuals un- der 25 years old and in patients over 60 years old. In previous studies, no positive association was found between age and the presence of $\mathrm{RD}^{\mathrm{Rio}}$ deletion (Lazzarini et al. 2007, Gibson et al. 2008, Barbosa et al. 2012, Weisenberg et al. 2012). The discrepancy on these results may be attributed to the fact that the latter studies considered the average or the median values rather than the age.

Considering the multivariate analysis, a positive association was found between alcohol consumption and the presence of $\mathrm{RD}^{\mathrm{Rio}}$ deletion. The former condition increased 1.6 times the chance of M. tuberculosis disease by this strain. A couple of studies have assessed the effect of alcohol consumption on the disease and found no positive association (Gibson et al. 2008, Dalla Costa et al. 2013).

Although we did not assess the nutritional status of the patients due to a lack of data, it is possible that the association of the disease with alcohol consumption may reflect the fact that an impaired nutritional status and a poor immune system favour M. tuberculosis infection. Lazzarini et al. (2007) found an association between weight loss and the presence of $\mathrm{RD}^{\text {Rio }}$ deletion, which supports the critical effect of malnutrition on the disease. There is evidence that the $\mathrm{RD}^{\mathrm{Rio}}$ deletion strains are associated with an increased transmissibility of tuberculosis bacillus (Lazzarini et al. 2007, Weisenberg et al. 2012). In general, alcoholic patients live in unhealthy and crowded environments and this could also explain this association. However, we did not evaluate the association of the socioeconomic conditions of the patients with alcohol consumption.

Previous studies have reported additional positive associations with $\mathrm{RD}^{\mathrm{Rio}}$ strains carrying the deletion. In a prospective study comprising 105 patients, Lazzarini et al. (2008) found 8.9 times more lung cavitation cases in patients infected by $\mathrm{RD}^{\mathrm{Rio}}$ deletion strains. We were not able to prove this association because with the secondary data used in this study we could not confirm the occurrence of cavitation.

In this study, no association was found between antituberculosis-drug resistance and $\mathrm{RD}^{\mathrm{R} i o}$ deletion. This can be explained by the low resistance prevalence in the studied strains. A Brazilian study conducted in Porto Alegre reported an $\mathrm{RD}^{\mathrm{Rio}}$ association with drug resistance (Dalla Costa et al. 2013). In the present study, 99\% of the samples with deletions were resistant, while only $63 \%$ of the M. tuberculosis wild strains presented multidrug resistance (MDR). The samples were obtained from a referral centre for MDR TB. It is possible that this association is the result of the high rate of resistance in the population, so that it does not represent the population with TB in Brazil. A study conducted in New York City reported a 1.6-fold increase in the resistance to isoniazid in the presence of $\mathrm{RD}^{\text {Rio }}$ deletion (Weisenberg et. al. 2012). Further studies are needed to verify the association of resistance with the RDRio deletion strain.

Barbosa et al. (2012) evaluated 272 patients in Rio de Janeiro. Using a univariate analysis, the authors did not find an association of the infection by $\mathrm{RD}^{\text {Rio }}$ deletion strains with epidemiological, clinical and radiological factors. These results demonstrate the need for further studies to assess the role of this strain as the cause of tuberculosis. 
The major limitation of this study was the use of secondary data. Considering the lack of important patient information regarding the epidemiological, clinical, radiological and bacteriological results, a bias must be considered in the interpretation of the associations reported in this work.

Finally, this study contributes to the knowledge of the association between infection by $M$. tuberculosis strains with $\mathrm{RD}^{\mathrm{Rio}}$ deletion and the 25-60 years-old age groups and/ or alcohol consumption. Future studies with larger sample sizes are needed to better understand these associations.

\section{AUTHORS' CONTRIBUTION}

EBM - Substantial contributions to conception and design, acquisition of data, analysis and interpretation of data. Drafting the article and critical review of intellectual content; LS and AJF - analysis and interpretation of data; HPPS, LR and VR - sample dispatch and phenotypic analyses; HMG and PS - critical review of intellectual content; CM - intellectual contribution; RC - intellectual contribution and statistical analysis; IMFDB - principal investigator of the research, substantial contributions to conception and design, drafting of the article and revising it critically for important intellectual content.

\section{REFERENCES}

Alix E, Godreuil S, Blanc-Potard AB. Identification of a Haarlem genotype-specific single nucleotide polymorphism in the $\mathrm{mgtC}$ virulence gene of Mycobacterium tuberculosis. J Clin Microbiol. 2006; 44(9): 2093-8.

Barbosa CB, Lazzarini LCO, Elias AR, Leung JAM, Ribeiro SB, da Silva MG, et al. Tuberculosis caused by $\mathrm{RD}^{\text {Rio }}$ Mycobacterium tuberculosis is not associated with differential clinical features. Int J Tuberc Lung Dis. 2012; 16(10): 1377-82.

Brosch R, Gordon SV, Marmiesse M, Brodin P, Buchrieser C, Eiglmeier K, et al. A new evolutionary scenario for the Mycobacterium tuberculosis complex. Proc Natl Acad Sci USA. 2002; 99(6): 3684-9.

Brudey K, Driscoll JR, Rigouts L, Prodinger WM, Gori A, Al-Hajoj SA, et al. Mycobacterium tuberculosis complex genetic diversity: mining the fourth international spoligotyping database (SpolDB4) for classification, population genetics and epidemiology. BMC Microbiol. 2006; 6: 23.

Caws M, Thwaites G, Dunstan S, Hawn TR, Lan NT, Thuong NT, et al. The influence of host and bacterial genotype on the development of disseminated disease with Mycobacterium tuberculosis. PLoS Pathog. 2008; 4(3): e1000034.

Comas I, Coscolla M, Luo T, Borrell S, Holt KE, Kato-Maeda M, et al. Out-of-Africa migration and Neolithic coexpansion of Mycobacterium tuberculosis with modern humans. Nat Genet. 2013; 45(10): 1176-82.

Coscolla M, Gagneux S. Does M. tuberculosis genomic diversity explain disease diversity? Drug Discov Today Dis Mech. 2010; 7(1): e43e9.

Dalla Costa ER, Lazzarini LC, Perizzolo PF, Díaz CA, Spies FS, Costa LL, et al. Mycobacterium tuberculosis of the $\mathrm{RD}^{\mathrm{Rio}}$ genotype is the predominant cause of tuberculosis and associated with multidrug resistance in Porto Alegre City, South Brazil. J Clin Microbiol. 2013; 51(4): 1071-7.

Eufrásio R, Alcobia M, Correia L. Pulmonary tuberculosis epidemiology in Coimbra's District (2000-2011): information is essential tounder stand high risk groups. Rev Port Pneumol. 2016; 22(4): 245-7.

Filliol I, Driscoll JR, van Soolingen D, Kreiswirth BN, Kremer K, Valétudie G, et al. Global distribution of Mycobacterium tuberculosis spoligotypes. Emerg Infect Dis. 2002; 8(11): 1347-9.

Fogel N. Tuberculosis: a disease without boundaries. Tuberculosis (Edinb). 2015; 95(5): 527-31.
Gagneux S, DeRiemer K, Van T, Kato-Maeda M, de Jong BC, Narayanan S, et al. Variable host-pathogen compatibility in Mycobacterium tuberculosis. Proc Natl Acad Sci USA. 2006; 103(8): 2869-73.

Gagneux S, Small PM. Global phylogeography of Mycobacterium tuberculosis and implications for tuberculosis product development. Lancet Infect Dis. 2007; 7(5): 328-37.

Gibson AL, Huard RC, van Pittius NCG, Lazzarini LCO, Driscoll J, Kurepina N, et al. Application of sensitive and specific molecular methods to uncover global dissemination of the major RDRio sublineage of the Latin American-Mediterranean Mycobacterium tuberculosis spoligotype family. J Clin Microbiol. 2008; 46(4): 1259-67.

Hirsh AE, Tsolaki AG, DeRiemer K, Feldman MW, Small PM. Stable association between strains of Mycobacterium tuberculosis and their human host populations. Proc Natl Acad Sci USA. 2004; 101(14): 4871-6.

Huard RC, Lazzarini LCO, Butler WR, van Soolingen D, Ho JL. PCR-based method to differentiate the subspecies of the Mycobacterium tuberculosis complex on the basis of genomic deletions. J Clin Microbiol. 2003; 41(4): 1637-50.

Lazzarini LC, Huard RC, Boechat NL, Gomes HM, Oelemann MC, Kurepina NE, et al. Discovery of a novel Mycobacterium tuberculosis lineage that is a major cause of tuberculosis in Rio de Janeiro, Brazil. J Clin Microbiol. 2007; 45(12): 3891-902.

Kamerbeek J, Schouls L, Kolk A, van Agterveld M, van Soolingen D, Kuijper S, et al. Simultaneous detection and strain differentiation of Mycobacterium tuberculosis for diagnosis and epidemiology. J Clin Microbiol. 1997; 35(4): 907-14.

Lazzarini LC, Spindola SM, Bang H, Gibson AL, Weisenberg S, Carvalho WS, et al. RD ${ }^{\text {Rio }}$ Mycobacterium tuberculosis infection is associated with a higher frequency of cavitary pulmonary disease. J Clin Microbiol. 2008; 46(7): 2175-83.

MS/SVS/DVE - Ministério da Saúde/Secretaria de Vigilância em Saúde/Departamento de Vigilância Epidemiológica. Manual nacional de vigilância laboratorial da tuberculose e outras micobactérias. Brasília: MS/SVS/DVE; 2008. 436 pp.

Oelemann MC, Gomes HM, Willery E, Possuelo L, Lima KVB, AllixBéguec $\mathrm{C}$, et al. The forest behind the tree: phylogenetic exploration of a dominant Mycobacterium tuberculosis strain lineage from a high tuberculosis burden country. PLoS ONE. 2011; 6(3): e18256.

Sola C, Filliol I, Legrand E, Mokrousov I, Rastogi N. Mycobacterium tuberculosis phylogeny reconstruction based on combined numerical analysis with IS1081, IS6110, VNTR, and DR-based spoligotyping suggests the existence of two new phylogeographical clades. J Mol Evol. 2001; 53(6): 680-9.

Sreevatsan S, Pan X, Stockbauer KE, Connell ND, Kreiswirth BN, Whittam TS, et al. Restricted structural gene polymorphism in the Mycobacterium tuberculosis complex indicates evolutionarily recent global dissemination. Proc Natl Acad Sci USA. 1997; 94(18): 9869-74.

Vinhas SA, Palaci M, Marques HS, de Aguiar PPL, Ribeiro FK, Peres $\mathrm{RL}$, et al. Mycobacterium tuberculosis DNA fingerprint clusters and its relationship with RD(Rio) genotype in Brazil. Tuberculosis (Edinb). 2013; 93(2): 207-12.

Weisenberg SA, Gibson AL, Huard RC, Kurepina N, Bang H, Lazzarini LC, et al. Distinct clinical and epidemiological features of tuberculosis in New York City caused by the RD ${ }^{\text {Rio }}$ Mycobacterium tuberculosis sublineage. Infect Genet Evol. 2012; 12(4): 664-70.

WHO - World Health Organization. Global Tuberculosis Report. Geneva: WHO; 2014. 304 pp.

Wysocki AD, Villa TCS, Arakawa T, Brunello MEF, Vendramini SHF, Monroe AA, et al. Latent tuberculosis infection diagnostic and treatment cascade among contacts in primary health care in a city of São Paulo state, Brazil: cross-sectional study. PLoS ONE. 2016; 11(6): e0155348. 